ного погрузка // Вестник Саратовского госагроуниверситета им. Н.И. Вавилова. - 2014. - № 6.

2. Васильчиков В.В., Жигунов С.А. Методы оптимизации геометрических параметров стрелы фронтального погрузчика // Научная мысль. 2015. - № 3. - С. 106.

3. Ерохин М.Н., Казаниев С.П., Карп А.В. Подъемно-транспортные машины. - М.: Колос, 2010. 335 c.

4. Казаринов В.М., Фохт Л.Г. Одноковшовые погрузчики в строительстве. - 2-е изд., перераб. М.: Стройиздат, 1975. - 239 с.

5. Родионов И. Б. Теория систем и системный анализ. - Режим доступа: http://victor-safronov. narod.ru/systems-analysis/lectures/rodionov/08.html.
Загоруйко Михаил Геннадьевич, канд. техн. наук, доцент, зав. кафедрой «Механика и инженерная графика», Саратовский государственный аграрный университет имени Н.И. Вавилова. Россия.

Елисеев Михаил Семенович, $\partial-p$ техн. наук проф. кафедры «Механика и инженерная графика», Саратовский государственный аграрный университет имени Н.И. Вавилова. Россия.

Васильчиков Валентин Владимирович, канд. техн. наук, доцент кафедры «Механика и инженерная графика», Саратовский государственный аграрный университет имени Н.И. Вавилова. Россия.

410056, г. Саратов, ул. Советская, 60.

Тел.: (8452) 74-96-51.

Ключевые слова: стрела фронтального погрузчика; 3D-прототипирование; твердотельное моделирование.

\title{
OPTIMIZATION OF GEOMETRICAL PARAMETERS OF BUILDING CONSTRUCTION ELEMENTS AT THEIR DESIGN WITH 3D-PROTOTYPING TECHNOLOGY
}

Zagoruyko Mikhail Gennadievich, Candidate of Technical Sciences, Associate Professor, Head of the chair "Mechanics and Engineering Graphics", Saratov State Agrarian University named after N.I. Vavilov. Russia.

Eliseev Mikhail Semenovich, Doctor of Technical Sciences, Professor of the chair "Me-chanics and Engineering Graphics", Saratov State Agrarian University named after N.I. Vavilov. Russia.

Vasylchikov Valentin Vladimirovich, Candidate of Technical Sciences, Associate Professor of the chair "Mechanics and Engineering Graphics", Saratov State Agrarian University named after N.I. Vavilov. Russia.
Keywords: front loader boom; 3D-prototyping; solid modeling.

It is considered design with 3D-prototyping technology of the front loader boom of the type PKU-08. It is received parametric equation describing the dependence of the force on the plunger of the power cylinder on its geometrical parameters. On its basis it is plotted effort against the load weight and height of the truck boom.

\section{ВОЗМОЖНОСТИ И ОСОБЕННОСТИ ПРОВЕДЕНИЯ ЭКСПЕРТИЗЫ ВОССТАНОВЛЕНИЯ ИЗМЕНЕННЫХ ИЛИ УНИЧТОЖЕННЫХ МАРКИРОВОЧНЫХ ОБОЗНАЧЕНИЙ НА РАЗЛИЧНЫХ МАТЕРИАЛАХ}

\author{
РАЙГОРОДСКИЙ Владимир Михайлович, Саратовский государственный аграрный \\ университет имени Н.И. Вавилова
}

\begin{abstract}
В работе рассмотрены методы проведения экспертизы восстановления измененных или уничтоженных маркировочных обозначений на различных материалах: металлах и сплавах, полимерах, дереве. Основное внимание уделено химическим методам восстановления, в т.ч. электрохимическому как наиболее легко реализуемым. Для отдельных материалов приведены составы травителей и электролитов, используемые при этом. Показано, ито для металлов и сплавов процесс восстановления зачастую сопровождается образованием на поверхности нерастворимых окислов темного изета, резко снинающих контраст и мешающих фиксащии восстановленнъх обозначений.
\end{abstract}

$\mathrm{H}$ еобходимость в восстановлении измененных или уничтоженных маркировочных обозначений возникает при расследовании различных категорий преступлений: краж транспортных средств, антиквариата, незаконного приобретения оружия, орденов, подделки пробирных клейм на изделиях из драгоценных металлов, маркировочных обозначений на пломбировочных запирающих устройствах и пр.

Данное исследование носит комплексный характер, включающее в себя не только определение вида материала с измененными или уничтоженными маркировочными 
обозначениями, но также выбор методов и средств для их восстановления. Если учесть, что контраст выявленных обозначений, как правило, крайне низок, то в отдельное исследование выделяют способы его увеличения, например, при помощи фотофиксации.

нанесение знаков на изделия производят одним из следующих способов:

штамповкой, которая в свою очередь подразделяется на механическую (с помощью матрицы и пуансона) и ручную (с помощью набора клейм, удар по которому наносят молотком или кувалдой). При ручном клеймении возможно использование кондуктора, уменьшающего отклонение знаков от линии строки. Одним из вариантов механизированного клеймения является накатка, используемая, в частности, для нанесения обозначений на блоки двигателей транспортных средств. В этом случае элементы клейма располагаются в обойме на боковой поверхности цилиндра и переносятся на деталь при движении этого цилиндра с усилием по поверхности;

гравированием, которое может быть электрическим, лазерным, механическим или ручным (с помощью штихеля);

Помимо указанных способов нанесение знаков может производиться отливкой, травлением, вырезанием, выжиганием.

Удаление знаков на изделиях производят, как правило, механическим воздействием на материал в месте расположения маркировки на всю глубину рельефа обозначения. При этом производят выравнивание поверхности изделия в месте нанесения маркировки. Чаще всего удаление обозначений производят шлифовкой наждачным кругом, напильником, наждачной бумагой, абразивным камнем. Реже используют зубила, ножовки или другие предметы с острой режущей кромкой. Процесс удаления маркировочных обозначений может производиться на токарных, фрезерных, строгальных и других станках, а также с помощью гравировальных инструментов. Кроме того, данный процесс может осуществляться высверливанием маркировочных обозначений с последующей заливкой отверстий легкоплавкими сплавами с последующей шлифовкой поверхности. Удаление маркировочных обозначений может производиться также с помощью химического травления. В этом случае в месте расположения маркировки наблюдается плавное заглубление рельефа с характерно выраженной поверхностью.
Восстановление удаленных маркировочных обозначений возможно лишь в тех случаях, когда при их нанесении происходит изменение каких-либо физико-механических или иных свойств материала: остаточных напряжений (деформаций) кристаллической структуры, растворимости, остаточного намагничивания, плотности, электропроводности и т.д.

Важно отметить, что для успешного восстановления маркировочных обозначений на изделиях эти изменения должны наблюдаться в структуре материала не только в местах набивки знаков, но и в нижележащих слоях, т.е. в слоях, оставшихся на изделии после удаления верхнего слоя материала с обозначением. Нижележащие слои несут информацию, необходимую для восстановления обозначений, а изменение структуры материала в этих слоях содержит информацию о «скрытом» в них изображении маркировочных знаков.

Качество восстановленного изображения будет зависеть от толщины информативного слоя, степени структурных либо иных изменений в нем, а также толщины удаленного слоя материала. Чем на большую толщину удалили материал, тем более расплывчаты, неотчетливы, слабо различимы будут контуры восстановленных обозначений. Толщина удаленного слоя, при которой изображение не будет восстановлено вовсе, зависит как от способа нанесения знаков, так материала, на который наносятся обозначения.

При нанесении знаков методом штамповки происходят деформация материала изделия, уплотнение его участков и возникновение остаточных напряжений. Деформация материала сопровождается измельчением отдельных кристаллитов, значительными искажениями (деформацией) кристаллической решетки.

Использование электрического или лазерного гравирования сопровождается изменением структуры материала, приводящим к его упрочнению, вследствие высокой температуры, создаваемой в месте воздействия. Для электрического гравирования таким воздействием является искровой разряд между электродом и материалом изделия, для лазерного гравирования, где этот эффект наблюдается в наибольшей степени, - излучение лазера, создающего мощное тепловой воздействие (тепловой удар), приводящий к значительным нарушениям зеренной структуры материала. Воздействие лазера может приводить к поверхностному упрочнению материала вследствие дробления зерен, разрушения 
межзеренных границ (созданию наклепанного слоя) $[4,5]$. Для деформированных материалов лазерное воздействие может явиться следствием чрезмерного роста зерен (рекристаллизации). В любом случае такое воздействие является причиной возникновения значительных изменений структуры материала, находящегося по бокам штрихов, а также под штрихами маркировочных обозначений. УПрочнение материала будет приводить к тому, что растворение материала при химическом или электрохимическом травлении будет происходить медленнее, чем в соседних областях. В результате восстановленные штрихи станут выпуклыми, будут выступать над маркировочной площадкой. Данный эффект наблюдали на алюминиевых и медных образцах [5], маркировочные обозначения на которые были нанесены с помощью лазерной установки «Мини Маркер 2 - М10», затем удалены и впоследствии восстановлены с помощью электрохимического травления (рис. 1).

Методы восстановления знаков на металлических изделиях можно условно разделить на три большие группы: физические, химические, электрохимические $[6,7]$.

К физическим методам относят различные варианты дефектоскопии: гамма- или рентгеновской, инфракрасной, вихретоковой. Получение изображения знаков на экране обусловлено различной интенсивностью излучения, прошедшего в местах с измененной вследствие набивки знаков структурой материала и в ненарушенных слоях.

К физическим относят также магнитопорошковый метод (магнитной суспензии). Ме-

a

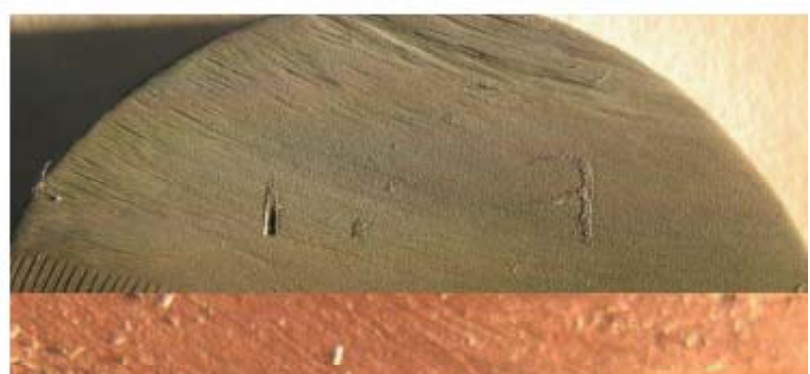

6

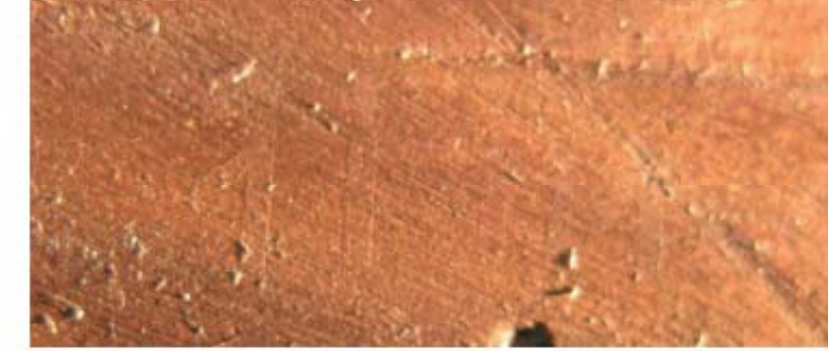

Рис. 1. Восстановленные штрихи маркировочных обозначений, полученных лазерным гравированием: а) на алюминиевом сплаве д1; б) на меди катодной тод применим только к ферромагнитным материалам и основан на фиксировании с помощью мелких ферромагнитных частиц различий в намагниченности насыщения образца, возникающей вследствие деформаций кристаллической решетки в местах набивки знаков.

Указанные методы являются неразрушающими, т.е. в результате проведения процесса восстановления образец остается в неизменном виде.

К частично разрушающим относится метод ионного травления, основанный на выбивании ионов из исследуемого материала при его бомбардировке ионами или электронами с высокой энергией. Эмиссия ионов происходит в первую очередь с участков, имеющих нарушения кристаллического строения, возникающих, в частности, при набивке маркировочных обозначений. Выявление обозначений происходит благодаря различию в скоростях распыления деформированной и недеформированной областей.

Химический и электрохимический методы основаны на растворении поверхностного слоя материала. При этом в первую очередь удаление материала происходит в тех местах, где имеются нарушения кристаллической структуры, возникающие, помимо прочего, и при нанесении маркировочных обозначений. Увеличение скорости растворения материала в местах с деформированной кристаллической решеткой обусловлено как нарушением химических связей между атомами, так и подбором специальных, т.н. селективных травящих растворов и электролитов.

Химический метод восстановления может быть реализован следующими способами:

опусканием изделия в ванну, заполненную травящим раствором. При этом поверхность, на которой будет проводиться процесс восстановления, должна быть покрыта раствором не менее чем на 5 мм, а остальная поверхность защищена слоем расплавленного воска, стеарина, парафина;

изготовлением вокруг маркировочной площадки бортиков из пластичного материала (пластилина, воска, стеарина, глины) и последующим заполнением «ванночки» необходимым раствором толщиной 3-5 мм. В процессе травления прореагировавший раствор можно обновлять, удаляя его из ванночки с помощью пипетки или фильтровальной бумаги и заменяя на новый. Данный способ является наиболее распространенным и универсальным и может быть применен для вос- 
становления знаков на массивных изделиях; обработкой маркировочной площадки ватным тампоном, смоченным травящим раствором. Несмотря на очевидные недостатки данного способа (увеличение времени и неравномерность процесса травления), он позволяет восстановить знаки на изделиях, маркировочные площадки на которых расположены вертикально и отсутствует возможность перевести их в горизонтальное положение.

Состав травящего раствора в каждом конкретном случае зависит от вида материала и технологии его изготовления. Для металлов и сплавов состав травителя определяется в первую очередь групповой принадлежностью либо самого исследуемого металла, либо металлов, составляющих сплав.

Например, для черных металлов (сталь, чугун) травящий раствор может быть приготовлен на основе смеси уксусной кислоты, соляной или азотной кислот, этилового спирта в различных концентрациях. Конкретный состав определяется составом исследуемого материала. Для изделий из цветных металлов травящий раствор изготавливают из азотной кислоты различной концентрации с добавлением соляной кислоты; для алюминия травителем является раствор едкой щелочи. На изделиях из золота травление проводят в смеси азотной и соляной кислот в соотношении 1:3 (т.н. «царская водка»).

Электрохимический метод восстановления, как и химический, основан на различии в скоростях растворения участков металла, в которых произошли структурные изменения, и остального объема, в котором эти изменения отсутствуют. Растворение металла в этом случае происходит под действием электрического тока в растворе электролита. Процесс электролитического травления может осуществляться несколькими способами:

погружением изделия в ванну с электролитом. При этом анодом является само изделие, а в качестве катода используют пластинку из нейтрального к действию электролита металла, например свинца. Электроды располагают параллельно на расстоянии 3-6 мм друг от друга;

изготовлением ванночки из пластилина, воска, стеарина и т.д. непосредственно на изделии, служащем анодом. Катод в виде проволочки располагается параллельно восстанавливаемой поверхности на расстоянии 3-5 мм от нее;

путем контакта участка, на котором проводится восстановление, с ватным тампоном, смоченным в электролите. Анодом в этом случае служит изделие, а катодом - пинцет, зажимающий ватный тампон и равномерно двигаемый вдоль поверхности. К пинцету при этом необходимо приложить отрицательный потенциал, а к изделию - положительный. В процессе электролитического травления необходимо следить за тем, чтобы движение тампона по поверхности изделия было плавным, без рывков, тампон должен быть постоянно обильно смочен электролитом. Быстрое высыхание тампона, наличие потрескивания при его движении указывают на необходимость уменьшения тока. Оптимальной считается такая сила тока, при которой наблюдается слабое «кипение» электролита в месте контакта тампона с поверхностью изделия, характеризуемое выделением пузырьков газа. Отсутствие этих признаков указывает на необходимость увеличения силы тока при проведении процесса. Подобным образом были восстановлены обозначения, представленные на рис. 1. Постоянное напряжение при этом подавали от источника питания «Instek GPS-303000», позволяющего проводить стабилизацию по напряжению и току до 30 В и 3 А соответственно. Исследуемый образец был подключен к положительному электроду (аноду), в качестве катода использовали стальной пинцет. Процесс проводили при напряжениях 5...10 В. Изменением напряжения корректировали скорость процесса. При этом величина тока составляла $0,3 \ldots 1,5 \mathrm{~A}$.

При реализации первого способа перед проведением процесса необходимо изолировать поверхность изделия, на которой не должна протекать реакция, с помощью материалов, нейтральных к действию электролита, например, расплавленного воска, стеарина, парафина, наносимых кисточкой или окунанием изделия. Можно для этого использовать различные лаки, клеи, растворы полимеров в органических растворителях, например целлулоида в ацетоне.

Электролитом для восстановления обозначений на изделиях из стали, как следует из [1-3], может служить 2-4\%-й раствор поваренной соли либо 1\%-й раствор серной кислоты. Последний раствор можно использовать также для восстановления обозначений на изделиях из меди и ее сплавов.

Для восстановления маркировочных знаков на изделиях из алюминия и его сплавов используют 1,5-2,5\%-й раствор едкой щелочи или раствор нитрата натрия. Этот же раствор применяется для электролитического травления стальных изделий и магниевых сплавов. 
Несмотря на кажущуюся простоту химического и электрохимического методов восстановления, они очень критичны к составу травителя или электролита. Последний выбирается исходя из элементного состава металла, на котором происходит процесс, в частности вида и содержания в нем легирующих компонентов. Это связано с тем, что процесс растворения металла начинается с окисления как основного компонента, так и легирующих примесей и перевода окислов в травящий раствор. При опробовании различных травителей и электролитов, в т.ч. указанных в литературе, мы зачастую наблюдали, что образовавшиеся окислы имеют темный цвет и нерастворимый характер, что не позволяло наблюдать выявленные штрихи и приводило к отрицательному характеру процесса восстановления (рис. 2). Данный эффект наблюдали в той или иной степени для всех исследуемых металлов и сплавов: чугуна и стали, сплавов из алюминия, магния и меди и т.д. Из этого следует, что выбор и оптимизация состава травителей и электролитов должны проводиться для каждой марки исследуемого металла и сплава.

Восстановление обозначений на изделиях из полимерных материалов проводят, как правило, с помощью химического метода $[6,7]$. Травителями при этом служат органические растворители, такие как дихлорэтан, диметилформамид, трихлорэтилен, четыреххлористый углерод, бензол, толуол, гексан, октан и т.д. Подбор травителей осуществляют, исходя из типа полимера и опытной проверки предполагаемого растворителя на нейтральных участках материала изделия.

Для наиболее часто употребляемых полимеров известны следующие травители:

для органического стекла - трихлорэтилен, дихлорэтан, хлороформ, ацетон. Перед проведением процесса полимер необходимо подогреть. Восстановление проводят с помощью ватного тампона, смоченного травителем. При этом нужно следить за тем, чтобы поверхность материала лишь непродолжительное время находилась в контакте с реактивом, в противном случае произойдет размягчение материала, приводящее к отрицательному результату процесса восстановления;

для полистирола - дихлорэтан, четыреххлористый углерод, трихлорэтилен;

для эбонита - трихлорэтилен. Места, подлежащие восстановлению, смачивают ватным тампоном, после чего поверхность освещают ультрафиолетовыми лучами. Вос-

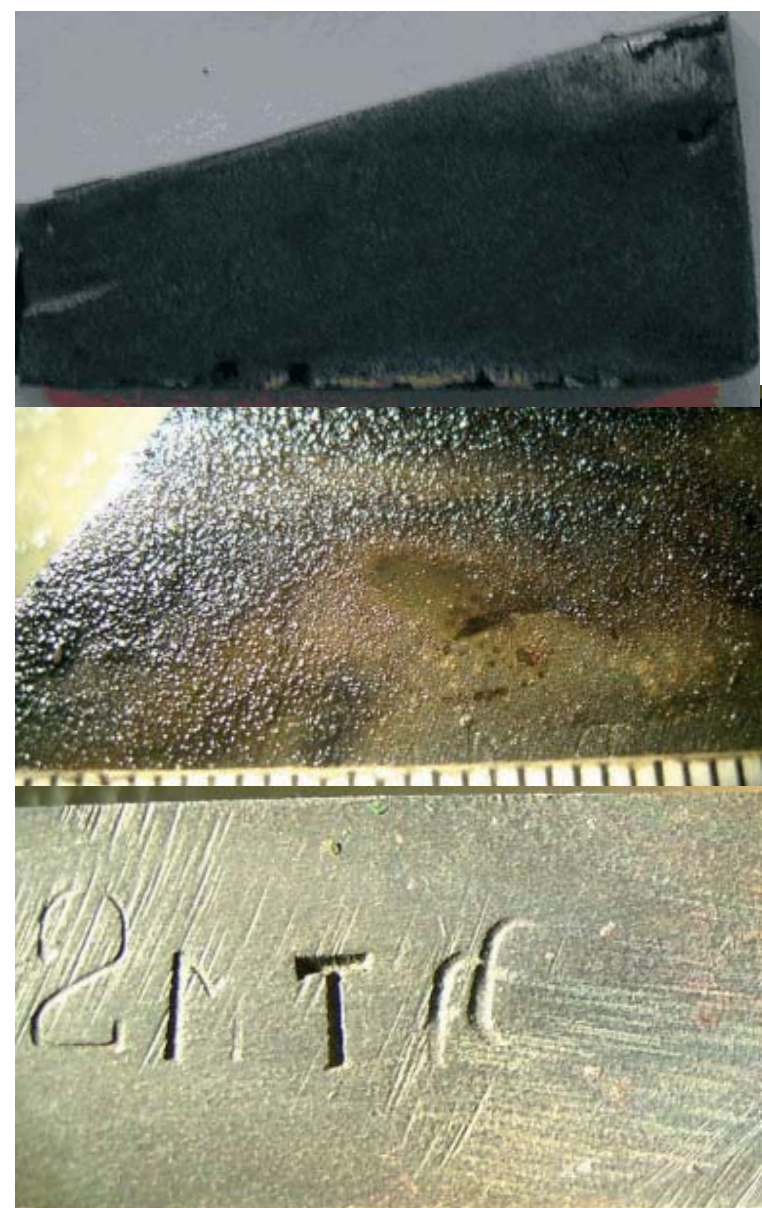

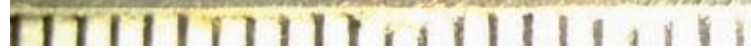

Рис. 2. Образование темных пленок окислов $($ а, б) и положительный результат восстановления маркировочных обозначений (в):

а) на образце из магниевого сплава МЛ-4 при его электролитическом растворении в смеси соляной, азотной кислот и дистиллированной воды; б) на образце серого чугуна СЧ-15 при его электролитическом растворении в растворе азотной кислоты в этиловом спирте; в) на том же образие при использовании электролита на основе 10\%-го раствора персульфата аммония

становленные цифры люминесцируют зеленым свечением, что дает возможность их зафиксировать. Для восстановления маркировок возможно использовать хлороформ, сероуглерод, бензол;

для гетинакса - бензол, пиридин. Под действием УФ-лучей восстановленные знаки люминесцируют зеленым свечением. Технология восстановления аналогична описанной для эбонита;

для вулканизированной фибры трихлорэтилен (время восстановления около двух часов);

- для фторопласта единственным растворителем является диметилформамид.

Знаки на пластмассовых изделиях из капрона, винипласта, текстолита и гетинакса выявляют с помощью растворителя на осно- 
ве ацетона, циклогексана, бензола

Следует отметить, что контраст изображений, выявленных на полимерных материалах, обычно значительно ниже, чем на металлах. Это связано с отсутствием кристаллической структуры в полимерах, что приводит лишь к уплотнению материала при набивке знаков. Твердость полимерных материалов значительно ниже, чем металлов, поэтому различие в плотности материала в местах набивки знаков и в остальном объеме незначительно, что определяет низкий контраст выявленных на полимерах знаков либо отрицательный результат восстановления.

Восстановление обозначений на изделиях из дерева производят с помощью увлажнения и отпаривания мест нанесения обозначений нагретым утюгом или паяльником при температуре их рабочей поверхности $200 . .250^{\circ} \mathrm{C}$.

Пропаривание производят с помощью ватного тампона, обильно смоченного водой. Утюг или паяльник необходимо прикладывать, не прижимая тампон. Воздействие на древесину сильно нагретыми парами воды приводит к тому, что деформированные при набивке знаков волокна древесины расправляются, и в результате проступает выпуклое рельефное изображение удаленных обозначений. Если в результате однократного пропаривания знаки не выявляются достаточно четко, необходимо повторить процедуру до появления четкого изображения.

Для восстановления рельефных изображений на древесине из смолистых пород поверхность перед проведением процесса необходимо увлажнить органическими растворителями (спиртом, эфиром, ацетоном и т.д.) для растворения смолы, мешающей набуханию волокон.

\section{СПИСОК ЛИТЕРАТУРЫ}

1. Борисов А.П., Скобелева Г.А. Выявление удаленных знаков на металлических и некоторых неметаллических предметах: практическое руководство. - М., 1960. - 62 с.

2. Исследование маркировочных данных автомототранспортных средств: учеб. пособие / Л.С. Митричев [и др.]. - М., 1995. - 78 с.

3. Поль К.Д. Естественнонаучная криминалистика (Опыт применения научно-технических средств при расследовании отдельных видов преступлений) / Пер. с нем. - М., 1985. - 320 с.

4. РайгородскийВ.М.Восстановлениемаркировочных обозначений на различных материалах // Современные пломбировочные устройства как объекты криминалистического исследования: материалы Междунар. науч.-практ. конф.; под ред. А.Г. Сухарева - Саратов, 2005. - С. 96-105.

5. Райгородский В.М., Саидов Д.А., Сафронов М.Ю. Восстановление маркировочных обозначений, полученных лазерным гравированием // Актуальные проблемы энергетики АПК: материалы VII Междунар. науч.-практ. конф.; под общ. ред. В.А. Трушкина. - Саратов, 2016. - С. 194-196.

6. Райгородский В.М., Хрусталев В.Н., Ермолаев С.А. Экспертиза восстановления измененных и уничтоженных маркировочных обозначений: учеб. пособие. - Саратов, 1999. - 72с.

7. Хрусталев В.Н., Райгородский В.М. Криминалистическое исследование веществ, материалов и изделий: курс лекций. - Саратов, 2005. - 492 с.

Райгородский Владимир Михайлович, канд. физ.-мат. наук, доиент кафедры «Инженерная физика, электрооборудование и электротехнологии», Саратовский государственный аграрный университет имени Н.И. Вавилова, Россия.

410056, 2. Саратов, ул. Советская, 60.

Тел.: (8452) 74-96-51.

Ключевые слова: маркировочные обозначения; восстановление маркировочных обозначений; электролит; травитель; металль; полимеры; дерево.

\section{CAPABILITIES AND FEATURES OF THE EXAMINATION OF THE RESTORATION OF ALTERED OR DESTROYED IDENTIFICATION NUMBERS ON DIFFERENT MATERIALS}

Raigorodskii Vladimir Mikhailovich, Candidate of Physical and Mathematical Sciences, Associate Professor of the chair "Engineering Physics, Electrical Equipment and Electrical Technologies", Saratov State Agrarian University named after N.I. VavilovюRussia.

Keywords: the markings, restoration of markings, electrolyte, etchant, metals, polymers, wood

The paper discusses the methods of examination restore the altered or destroyed identification num- bers for different materials: metals and alloys, polymers, wood. The focus is on chemical remediation methods, including electrochemical, as the most easily implemented. For certain materials the formulations of etchants and electrolytes used in it. It is shown that for metals and alloys in the repair process is often accompanied by formation on the surface of the insoluble oxides of a dark color, sharply reduces contrast and prevents the fixing of recovered symbols. 